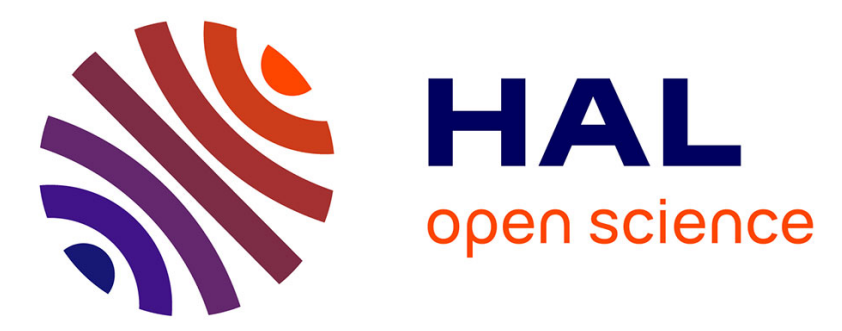

\title{
A Low-Noise and Quasi-Ideal DC Current Source Dedicated to Four-Probe Low-Frequency Noise Measurements
}

Jean-Marc Routoure, Sheng Wu, Carlo Barone, Laurence Méchin, Bruno Guillet

\section{To cite this version:}

Jean-Marc Routoure, Sheng Wu, Carlo Barone, Laurence Méchin, Bruno Guillet. A LowNoise and Quasi-Ideal DC Current Source Dedicated to Four-Probe Low-Frequency Noise Measurements. IEEE Transactions on Instrumentation and Measurement, 2020, 69 (1), pp.194. 10.1109/TIM.2019.2890891 . hal-02273188

\section{HAL Id: hal-02273188 \\ https://hal.science/hal-02273188}

Submitted on 4 Jan 2021

HAL is a multi-disciplinary open access archive for the deposit and dissemination of scientific research documents, whether they are published or not. The documents may come from teaching and research institutions in France or abroad, or from public or private research centers.
L'archive ouverte pluridisciplinaire HAL, est destinée au dépôt et à la diffusion de documents scientifiques de niveau recherche, publiés ou non, émanant des établissements d'enseignement et de recherche français ou étrangers, des laboratoires publics ou privés. 


\title{
A low noise and quasi-ideal DC current source dedicated to four-probe low frequency noise measurements
}

\author{
J.M. Routoure, S. Wu, C. Barone, L. Méchin, B. Guillet
}

\begin{abstract}
In this paper, a DC current source dedicated to four-probe low frequency noise measurements is presented. An output impedance value of $3 \mathrm{M} \Omega$ with a maximum output current of $1.5 \mathrm{~mA}$ was achieved. The white noise level of the current source was measured to be $4 \times 10^{-23} \mathrm{~A}^{2 \cdot} \cdot \mathbf{H z}^{-1}$ with a corner frequency of $30 \mathrm{~Hz}$. Thanks to its quasi-ideal behavior in terms of noise level and high output impedance value, this current source can be used to measure the intrinsic noise of materials using four-point measurements without any experimental or analytical corrections.
\end{abstract}

Index Terms-Low-frequency noise (LFN), DC current source, four-probe measurement

\section{INTRODUCTION}

$\mathrm{C}$ ompared to other classical techniques such as capacitance-voltage or deep level transient spectroscopy measurements, the $1 / \mathrm{f}$ low frequency noise measurements are one of the most sensitive tool to investigate material or device quality and performance [1]. For example, noise measurements allow to perform material comparison for sensor applications [2] or deep level spectroscopy on semiconductors devices [3], and to identify the impact of some technological steps or technologies on the degradation of device performances [4-7]. Despite all these advantages, one limitation of this technique is the difficulty to remove all the extrinsic low frequency noise sources to be sure that the measured noise comes only from the device or material under test. In the case of material characterization, it is well known that the four-probe configuration is adequate to remove contact contribution in DC and even white noise measurements. This is not the case for $1 / \mathrm{f}$ noise due to the possible noise contribution in voltage or current contacts.

Submission date: July 11, 2018

J.M. Routoure, B. Guillet and L. Méchin are with Normandie Univ, UNICAEN, ENSICAEN, CNRS, GREYC, 14000 Caen, France (e-mail: jean-marc.routoure@unicaen.fr, laurence.mechin@ensicaen.fr, and bruno.guillet@unicaen.fr).

$\mathrm{S}$. Wu was with Normandie Univ, UNICAEN, ENSICAEN, CNRS, GREYC, 14000 Caen, France. He is now with Tianjin University, 300072, China (e-mail: wusheng9201@ hotmail.com).

C. Barone is with the Dipartimento di Fisica "E.R. Caianiello" and CNR-SPIN, Università di Salerno, 84084 Fisciano, Salerno, Italy (email: cbarone@unisa.it).
In this paper we show that using a DC current source with both high output impedance value and moderate low frequency noise level in a four-probe configuration allows to obtain a direct measurement of the intrinsic noise sources of material without any experimental or analytical corrections (section II). The proposed circuit based on low noise operational amplifiers (OpAs) is described and compared with other current sources, operating in the low frequency range, found in literature (Section III). For the sake of clarity, here it is important to stress that other current source designs, having high output impedance, have been already developed for Electrical Impedance Tomography applications [8]. However, they are essentially dedicated to high frequency investigations and, therefore, do not cover the topic of this paper. The low noise characteristics of the proposed quasi-ideal DC current source, which looks like Howland current pump design [9], will be highlighted in this paper. In section IV, the performance of the proposed current source is demonstrated by measurements performed on a low noise material (namely $\mathrm{La}_{0.7} \mathrm{Sr}_{0.3} \mathrm{MnO}_{3}$ ) that exhibits a non-negligible contact noise contribution.

\section{FOUR- PROBE LOW FREQUENCY NOISE MEASUREMENTS}

The equivalent electrical circuit is presented in figure 1. First, four contact pads have to be realized on the sample. The DC current source is connected to two current pads (noted IP and IM) and DC or AC voltage is measured using two voltage pads (noted VP and VM, respectively). In this configuration, the sample electrical resistance $R_{M}$ can be deduced from the ratio between the measured voltage and the bias current, without any errors caused by the current and voltage contact resistances (noted $R_{C I}$ and $R_{C V}$, respectively). For simplicity, it is assumed that $R_{C I}\left(R_{C V}\right)$ is the sum of the current contact (voltage contact) resistances of the two probes IP and IM (VP and VM).

The voltage noise spectral density $e_{n V P V M}^{2}$ is the voltage noise measured at the voltage pads of the sample. It can be measured by a spectrum analyzer connected at the differential amplifier output that computes the output noise spectral density $e_{\text {nout }}^{2}$. Here, we assume that the frequencies are low enough to neglect all parasitic capacitances. For the differential amplifier, it is also considered that its input impedance is very high, its current noise can be neglected (with the choice of operational amplifiers based on FETs), and the voltage gain $K$ is constant over all the frequency range of interest so that $e_{n V P V M}^{2}$ is directly given by $e_{\text {nOUT }}^{2} / K^{2}$. 


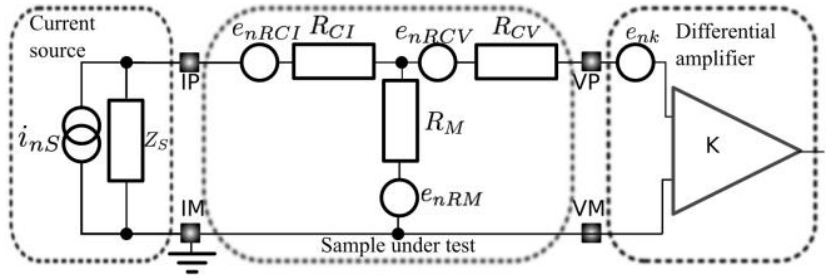

Fig. 1. Schematic representation of the four-probe technique showing the different elements of the circuit and the different noise sources. The resistance of the film under test is $R_{M}$. Its voltage noise is $e_{n R M} . R_{C I}$ and $R_{C V}$ are the current and voltage contact resistances, respectively. $e_{n R C I}$ and $e_{n R C V}$ are their associated voltage noise. The current source has an output impedance $Z_{S}$ and its current noise is $i_{n s}$. The voltage noise of the differential amplifier (of differential gain $K$ ) is $e_{n k}$. It is assumed that the current noise of the high input impedance differential amplifier can be neglected.

Each element introduces its own electrical noise, which may consist in white noise and excess noise. The following noise sources are related to the noise spectral densities:

- $e_{n R C I}$, the voltage noise spectral density of the current contact resistance,

- $e_{n R M}$, the voltage noise spectral density of the film,

- $e_{n R C V}$, the voltage noise spectral density of the voltage contact resistance,

- $e_{n k}$, the voltage noise spectral density of the differential amplifier.

In order to simplify the analysis, it will be assumed that the amplifier noise and the voltage contact noise can be neglected (in practice, these two contributions can be estimated when no DC current flows into the device and can be subtracted from all the measurement performed when a DC current is applied). Therefore, the noise spectral density $e_{n V P V M}^{2}$ at the differential amplifier input can be defined as:

$$
\begin{aligned}
e_{n V P V M}^{2}=\frac{e_{\text {nOUT }}^{2}}{K^{2}} & =e_{n R C I}^{2} \frac{R_{M}^{2}}{\left|Z_{E Q}\right|^{2}}+i_{n S}^{2} \frac{\left|Z_{S}\right|^{2} R_{M}^{2}}{\left|Z_{E Q}\right|^{2}} \\
& +e_{n R M}^{2} \frac{\left|R_{C I}+Z_{S}\right|^{2}}{\left|Z_{E Q}\right|^{2}}
\end{aligned}
$$

where

$$
\mathrm{Z}_{\mathrm{EQ}}=\mathrm{Z}_{\mathrm{S}}+\mathrm{R}_{\mathrm{CI}}+\mathrm{R}_{\mathrm{M}}
$$

The goal is the removal of all the extrinsic contributions and, consequently, the measurement of the intrinsic material noise. This can be obtained by choosing appropriate experimental conditions, so that the sample noise contribution dominates and the factor $\left|R_{C I}+Z_{S}\right|^{2} /\left|Z_{E Q}\right|^{2}$ equals unity. This could be achieved if the DC current source is ideal, i.e. if its output impedance $Z_{S}$ is infinite and its noise $i_{n S}$ is negligible. It can be shown that this is achieved if

$$
\text { and } \begin{gathered}
\left(\left|R_{C I}+Z_{S}\right| / R_{M}\right)^{2} \gg\left(e_{n R C I} / e_{n R M}\right)^{2} \\
i_{n S}^{2} \ll\left(e_{n R M} / R_{M}\right)^{2} \cdot\left|Z_{S}+R_{C I}\right|^{2} /\left|Z_{S}\right|^{2}
\end{gathered}
$$

Only an approximation of this ideal case can be reached. In practice, we will look for a quasi-ideal DC current source that exhibits the highest output impedance value as possible and the smallest noise level in the frequency range of interest.

Few publications dealing with the realization of quasi-ideal low noise DC current sources can be found and the proposed circuits are often dedicated to specific applications. In [10], the source allows to drive a stable and high current in magnetic coils. The proposed circuit is based on low noise OpAs associated with bipolar transistors: the maximum output current is $300 \mathrm{~mA}$, the output impedance can be evaluated to $10 \mathrm{M} \Omega$ and the white noise level is $6.3 \times 10^{-18} \mathrm{~A}^{2} \cdot \mathrm{Hz}^{-1}$ with a corner frequency of $1 \mathrm{~Hz}$ ( $c f$. table 1). In [11], the application consists in biasing a superconducting qubit with a long-term stability. The circuit consists in the classical representation of a DC current source: a well-controlled DC voltage source based on operational amplifiers in series with a constant metallic resistance: the output current is $275 \mu \mathrm{A}$, the output impedance is $10 \mathrm{k} \Omega$ and the white noise level is $0.7 \times 10^{-24} \mathrm{~A}^{2} \cdot \mathrm{Hz}^{-1}$ with a corner frequency of $100 \mathrm{~Hz}$. In order to measure low frequency noise, Talukdar et al. [12] and Ciofi et al. [13] have reported very low noise current sources based on JFET transistors, showing current noise densities of $10^{-22} \mathrm{~A}^{2} \cdot \mathrm{Hz}^{-1}$ with an output current of $10 \mathrm{~mA}$ and a corner frequency of $1 \mathrm{~Hz}$ and $3.5 \times 10^{-21}$ $\mathrm{A}^{2} \cdot \mathrm{Hz}^{-1}$ with an output current of $100 \mathrm{~mA}$ and a corner frequency of $1 \mathrm{~Hz}$, respectively. The output impedance values are not given but thanks to the JFET transistor datasheets, one can estimate an output impedance for these two references around $10 \mathrm{k} \Omega$. Scandurra et al. proposed also a programmable very low noise current source using a JFET device acting as high impedance current source and a MOSFET driver [14]. An automatic measurement system for direct-current, capacitance-voltage, and gate-drain low frequency noise characterization of field effect transistors using Source Measurement Units of a semiconductor parameter analyzer HP4155B has been reported $[15,16]$. Finally, the more recent and complete description of a four-probe setup can be found in [17]. In this paper, a basic DC current source that consists in a filtered DC voltage in series with a metallic resistance is used. The output impedance is given by the resistance value used and the white noise level by its thermal noise. Due to the non-ideality of the current source, two measurements are required, one in the four-probe configuration and the other in the two probe configuration (when the differential amplifier is connected to the IP and IM pads). Moreover, the analysis needs numerical corrections to remove all the extrinsic noise contributions.

\section{THE LOW NOISE HIGH OUTPUT IMPEDANCE DC CURRENT SOURCE}

\section{A. Circuit design and DC output current}

The schematic of the proposed circuit for a low noise high output impedance DC source is given in figure 2. The source is 


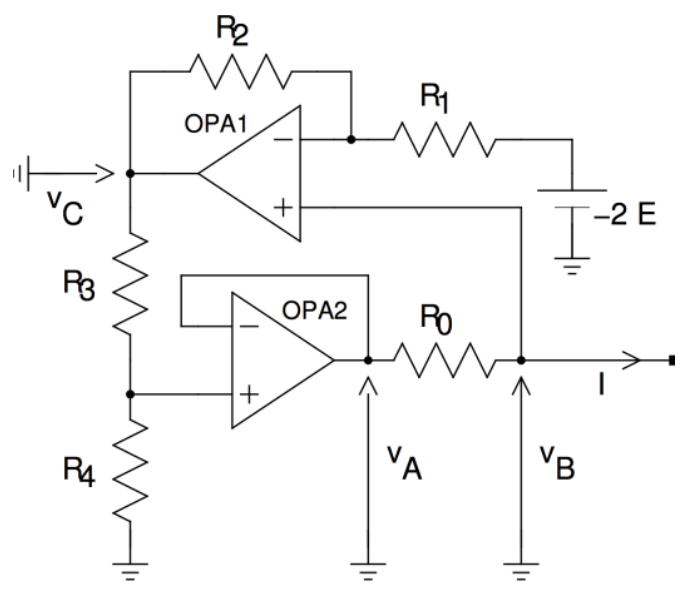

Fig. 2. Schematic of the proposed DC current source circuit. If resistance $R_{1}$ to $R_{4}$ are equal, the circuit ensures that $v_{A}=v_{B}+E$. The resistance $R_{0}$ sets the output current DC value, the small signal output impedance and the noise performance.

built using two low noise OpAs and several resistances. The first OpA acts as a summing-subtracting amplifier whereas the second one is a simple follower. The purpose of the circuit is to measure the voltage $v_{B}$ and to add an external DC voltage $2 E$ so that the voltage $v_{A}$ is equal to $v_{B}+E$. This is achieved if $R_{1}=R_{2}$ and $R_{3}=R_{4}$.

Assuming that the OpAs are ideal and that the four electrical resistances are equal, the output current I in $R_{0}$ is given by:

$$
I=\frac{v_{A}-v_{B}}{R_{0}}=\frac{E}{R_{0}}
$$

The DC output current is limited by the saturation voltage $\mathrm{V}_{\mathrm{SAT}}$ of the first OpA (named as OPA1). Since $v_{C}=2 v_{B}+2 E$, assuming that the biased device is an electrical resistance $R_{M}$ $\left(v_{B}=R_{M} \cdot I\right)$, it can be shown using previous equation that:

$$
|I| \ll \frac{\left|V_{S A T}\right|}{2\left(R_{M}+R_{0}\right)}
$$

The maximum output current $I_{\text {OUT }}$ is found to be about $6.8 \mathrm{~mA}$ for $R_{0}=1 \mathrm{k} \Omega=10 \cdot R_{M}$ and $V_{S A T}=15 \mathrm{~V}$. For smaller values of $R_{0}$, the current limitation is due to the OpAs (and can be as high as about $20 \mathrm{~mA}$ ).

\section{B. Small signal output impedance}

In order to predict the small signal output impedance value, one has to take into account the open-loop gain $A_{D}$ of the OpAs and the fact that the condition $R_{I}=R_{2}=R_{3}=R_{4}$ can only be approximated in practice. A first-order low-pass filter approximation for the OpA open-loop gain $A_{D}$ is used $\left(A_{D}=\right.$ $A_{D 0} /\left(1+j \cdot \frac{f}{f_{0}}\right)$ ).

We also introduce the parameters $\alpha$ and $\varepsilon$ to model the small mismatches between the four real electrical resistances in the real circuit. These parameters are defined by $R_{1}=\alpha \cdot R_{2}$ and $R_{3}=(\alpha+\varepsilon) \cdot R_{4}$. The parameter $\alpha$ models the quasi equality between the four resistances and the whole mismatch between these resistances can be written using only $\varepsilon$. The four resistances have been chosen to be as identical as possible so that $\alpha=1$ and $\varepsilon \sim 0$ (with respect to the previous conditions $\mathrm{R}_{1}=$ $\mathrm{R}_{2}$ and $\mathrm{R}_{3}=\mathrm{R}_{4}$ ). One can finally express the small signal output impedance $Z_{S}$ by:

$$
Z_{S}=\left(\frac{(1+\alpha)+(1+\alpha+\varepsilon)(1+\alpha) A_{D}+(1+\varepsilon) A_{D}^{2}}{(1+\alpha)+(1+\alpha+\varepsilon)(1+\alpha) A_{D}+\varepsilon A_{D}^{2}}\right) \cdot R_{0}
$$

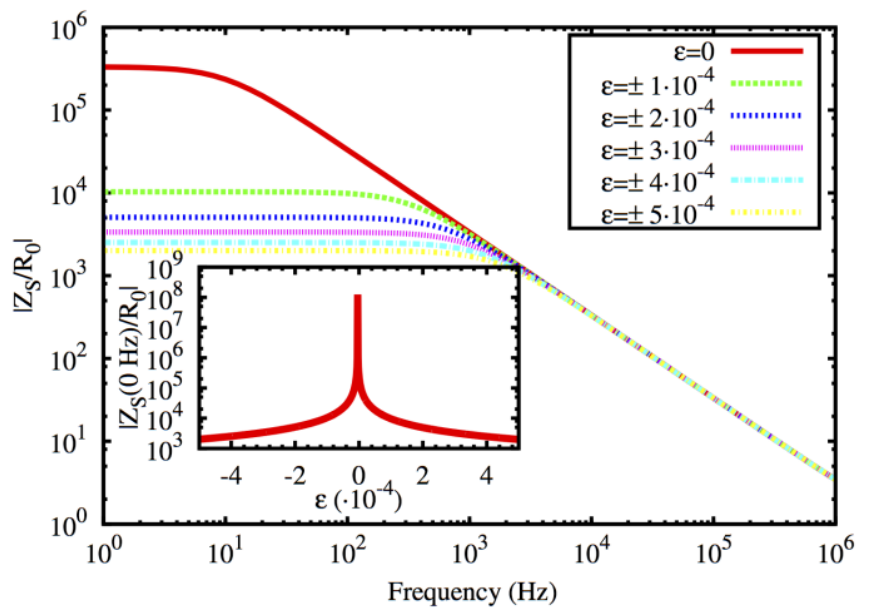

Fig. 3. Magnitude of the output impedance $\left|Z_{S} / R_{0}\right|$ versus frequency for different values of the mismatch $\varepsilon$ between $R_{3}$ and $R_{4}$. A first order low pass behavior of $Z_{S}$ is obtained. Inset shows the DC output impedance versus $\varepsilon$.

It shows that the output impedance is proportional to $R_{0}$. In order to investigate the output impedance variations with the mismatches in the resistance values, the calculated values of the output impedance $\left|Z_{S} / R_{0}\right|$ are plotted in figure 3 versus frequency for several $\varepsilon$ values close to 0 . The inset shows the $\mathrm{DC}$ value versus $\varepsilon$. For this calculation, classical values for standard OpAs have been assumed (i.e., $A_{D 0}=10^{6}$ and $f_{0}=$ $10 \mathrm{~Hz}$ ).

These calculations show that only a discrete value of $\varepsilon$ very close to 0 allows to obtain a DC output impedance almost equal to $10^{5}$ times the resistance $R_{0}$, otherwise a more reasonable factor of about $10^{3}$ is obtained. Figure 4 shows that the output impedance decreases with increasing frequency with a slope close to $20 \mathrm{~dB}$ per decade due to the frequency response of the OpA. A compromise needs to be done between high value of the output impedance and the range of frequencies for which these high values are obtained.

In practice, when using resistances with very low temperature coefficient, a low mismatch of less than $5 \times 10^{-4}$ between resistance values could be easily achieved. The current source output impedance $\left|Z_{S}\right|$ is therefore expected to be at least $10^{3}$ times the value of $R_{0}$ at low frequency (up to around one $\mathrm{kHz}$ ). Measurements of transfer-function using sweep mode of spectrum analyzer as excitation signals instead of the DC voltage $2 E$ have been performed to estimate the output impedance. The modules of measured transfer functions with two different fixed electrical resistor $R_{M}$ value $(10 \mathrm{k} \Omega$ and 1 
$\mathrm{M} \Omega$ ) with $R_{0}=1 \mathrm{k} \Omega$ are plotted in figure 4 . The ratio of these two measurements allows estimating the source output impedance assuming that amplifier gain and the resistance $R_{0}$ values are the same for the two measurements.

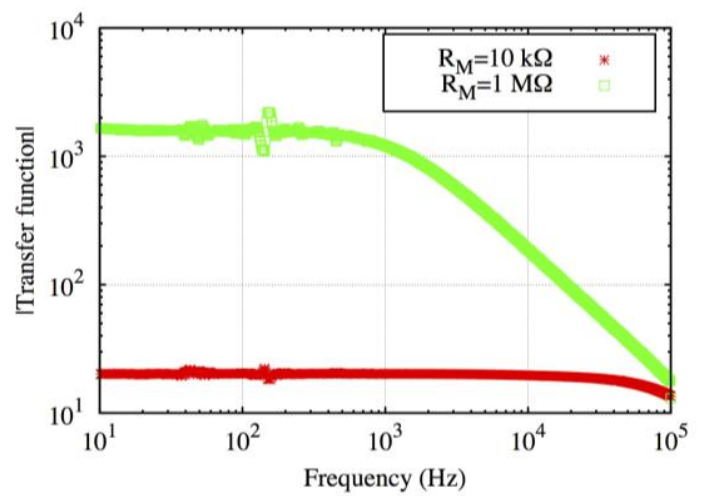

Fig. 4. Module of measured transfer functions for 2 different $R_{M}$ value and $R_{0}=1 \mathrm{k} \Omega$ (128 averages).

Figure 5 shows the measured output impedance versus frequency. The proposed model is also plotted and a very good agreement is found between measurements and theory: as expected, the output impedance is, at low frequency, proportional to $R_{0}$ with a factor higher than one thousand. A first order behavior is also obtained at intermediate frequency as predicted. The comparison between measurements and model is consistent with a value of $\varepsilon$ around $2.5 \times 10^{-4}$ in the realized circuit.

Finally, with this mismatch value, the output impedance is at least one thousand time the resistance $R_{0}$ at frequencies up to $1 \mathrm{kHz}$.

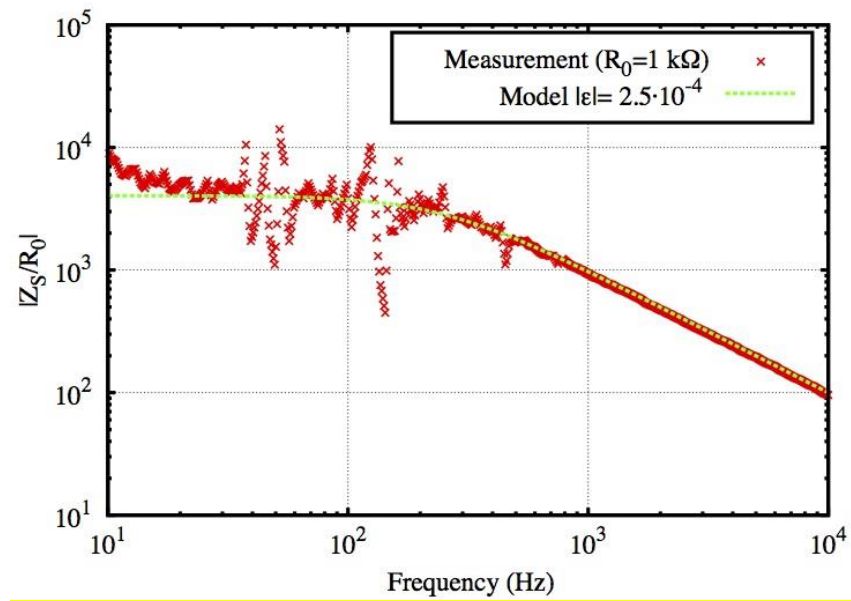

Fig. 5. Small signal output impedance $Z_{S}$ divided by $R_{0}$. Comparison between measurements and model for $R_{0}=1 \mathrm{k} \Omega$. In the realized circuit, the mismatch between resistances must be close to $2.5 \times 10^{-4}$.

\section{Noise level}

The noise of the current source is due to the thermal noise of each resistance (of spectral density $e_{n R i}^{2}$ ) and to the equivalent voltage noise of the two OpAs (of spectral densities $e_{n A}^{2}$ and $e_{n B}^{2}$ ). Due to the small resistance values connected at the input of the OpAs, the equivalent current noise can be neglected. To ensure that this assumption is verified, JFET based OpAs (AD 743) has been used in the realized circuit.

The noise of the external voltage source is also neglected here because in practice, this external voltage can be generated either by batteries or by a filtered voltage source using a very low frequency low-pass filter. Assuming $R_{1}=R_{2}=$ $R_{3}=R_{4}=R$, the current white noise spectral density $i_{n s}^{2}$ of the source is given by:

$i_{n S}^{2}=\frac{4 k_{B} T}{R_{0}}+\frac{4 k_{B} T R+e_{n A}^{2}+e_{n B}^{2}}{R_{0}^{2}}$

with $k_{B}=1.38 \times 10^{-23} \mathrm{~J} \cdot \mathrm{K}^{-1}$ the Boltzmann constant and $T$ the temperature in kelvin. The measured current noise spectral density $i_{n S}^{2}$ of the current source is plotted in figure 6 for three values of $R_{0}$ and $R=464 \Omega$. Only white noise is observed for $R_{0}=100 \mathrm{k} \Omega$, whereas, the low frequency noise of the OpAs has to be taken into account for $R_{0}=1 \mathrm{k} \Omega$ and $10 \mathrm{k} \Omega$.

The measured white noise level as well as its expected value are plotted in the inset of figure 6 and show a very good agreement in the realized circuit $\left(e_{n A}^{2}+e_{n B}^{2}+4 \cdot k_{B} \cdot T \cdot\right.$ $\left.R=25 \times 10^{-18} \mathrm{~V}^{2} \cdot \mathrm{Hz}^{-1}\right)$. When $R_{0}$ is higher than $1.5 \mathrm{k} \Omega$, the current source white noise is dominated by the thermal noise of the resistance $R_{0}$.

The low frequency noise is due to the OpAs and its contribution decreases with $R_{0}^{2}$. Therefore, the current source low frequency noise almost disappears when $R_{0}$ is higher than $10 \mathrm{k} \Omega$. With $R_{0}=1 \mathrm{k} \Omega, i_{n S}^{2}=2 \times 10^{-21} \mathrm{~A}^{2} \cdot \mathrm{Hz}^{-1}$ at $1 \mathrm{~Hz}$.

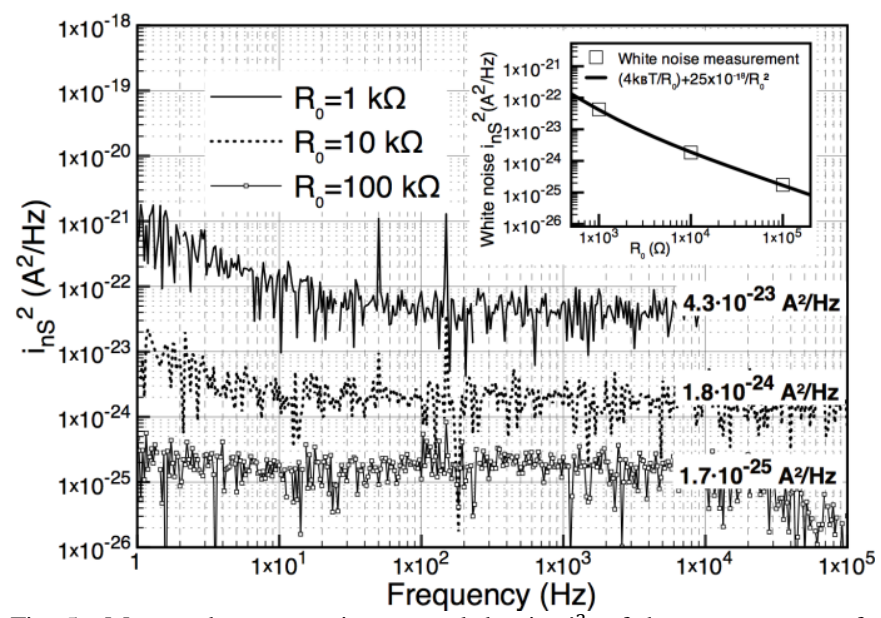

Fig. 5. Measured current noise spectral density $i_{n s}^{2}$ of the current source for three values of the resistance $R_{0}$. Except for $R_{0}=1 \mathrm{k} \Omega$, mostly white noise is measured. Numerical values of the white noise level are indicated for each value of $R_{0}$. Inset shows the good agreement between the measured white noise spectral density and its expected values.

Finally, for $R_{0}=1 \mathrm{k} \Omega$ (values of $R_{0}$ that gives almost the highest output current with reasonable low noise performance) the maximum output current is $1.5 \mathrm{~mA}$, the output impedance can be estimated around $3 \mathrm{M} \Omega$ below $1 \mathrm{kHz}$ and the noise level is $4 \times 10^{-23} \mathrm{~A}^{2 \cdot} \mathrm{Hz}^{-1}$ with a corner frequency of $10 \mathrm{~Hz}$. These values are summarized in table I. 
TABLE I

SUMMARY OF PUBLISHED DC CURRENT SOURCE CHARACTERISTICS

\begin{tabular}{c|c|c|c|c}
\hline \hline Reference & $\begin{array}{c}\text { Maximum } \\
\text { output } \\
\text { current } \\
(\mathrm{mA})\end{array}$ & $\begin{array}{c}\text { Output } \\
\text { impedance } \\
(\Omega)\end{array}$ & $\begin{array}{c}\text { White } \\
\text { noise level } \\
\left(\mathrm{A}^{2} \cdot \mathrm{Hz}^{-1}\right)\end{array}$ & $\begin{array}{c}\text { Corner } \\
\text { frequency } \\
(\mathrm{Hz})\end{array}$ \\
\hline $\begin{array}{c}\text { Ross } \text { et al. } \\
{[10]}\end{array}$ & 300 & $10 \mathrm{M} \Omega$ & $6.3 \times 10^{-18}$ & 1 \\
$\begin{array}{c}\text { Linzen } \text { et al. } \\
{[11]}\end{array}$ \\
$\begin{array}{c}\text { Talukdar } \text { et al. } \\
{[12]}\end{array}$ \\
$\begin{array}{c}\text { Ciofi } \text { et al. } \\
{[13]}\end{array}$
\end{tabular}

${ }^{\mathrm{a}}$ for $R_{0}=1 \mathrm{k} \Omega$

${ }^{\mathrm{b}}$ below $1 \mathrm{kHz}$

The voltage noise spectral density $e_{n V P V M}^{2}$ is the voltage noise measured at the voltage pads of the sample. It can be measured by a spectrum analyzer connected at the differential amplifier output that computes the output noise spectral density $e_{\text {noUT }}^{2}$. Here, we assume that the frequencies are low enough to neglect all parasitic capacitances. For the differential amplifier, it is also considered that its input impedance is very high, its current noise can be neglected (with the choice of operational amplifiers based on FETs), and the voltage gain $\mathrm{K}$ is constant over all the frequency range of interest so that $e_{n V P V M}^{2}$ is directly given by $e_{\text {nout }}^{2} / K^{2}$.

\section{Conclusion}

Table 1 summarizes and compares the maximum output current, the output impedance, the white noise level and the corner frequency of different published DC current sources. It is clear that a universal circuit with optimal characteristics, i.e. low noise, high output impedance and high maximum current does not exist. Best results in terms of noise (especially at low frequency) and maximum output current have been obtained with JFET based circuits but the output impedance is then rather small and not suitable for low frequency noise four-probe measurement. On the contrary, the use of OpAs leads to high output impedance value but it also exhibits higher noise level [10]. The proposed circuit is not the best one in case of noise performances and maximum output current but it is the only one that exhibits both a high output impedance with a sufficiently low noise level with a reasonable maximum output current. In the next section, it will be shown that these performances are optimum to measure intrinsic low frequency noise of material without any corrections.

\section{EXPERIMENTAL VALIDATION}

This low noise current source has been developed in the framework of low frequency noise characterization of different materials [17-22]. In order to demonstrate the improved performances of the source, some results measured in $\mathrm{La}_{0.7} \mathrm{Sr}_{0.3} \mathrm{MnO}_{3}$ (LSMO) thin films deposited onto $\mathrm{SrTiO}_{3}$ substrates are shown. This kind of sample exhibits several interesting properties both for theoretical or application point of views and has been strongly studied over the last decades [2, 23-26]. Sample fabrication details can be found in [26].

It has also been previously shown that this kind of sample exhibits a high level of the current contact noise [17]. The film thickness is $150 \mathrm{~nm}$, the width and the length of the devices which act as a simple resistance are $100 \mu \mathrm{m}$ and $150 \mu \mathrm{m}$, respectively. They were patterned so that two current pads and two voltage pads are available. Finally, the LSMO sample exhibits an electrical resistance value $R_{M}=503 \Omega$.

Two current sources were used to bias the device with the same DC current: the source described in the previous section and the "classical" one with a low-pass filtered DC voltage in series with a resistance named $R_{0}$ ("basic source") shown in figure 7 .

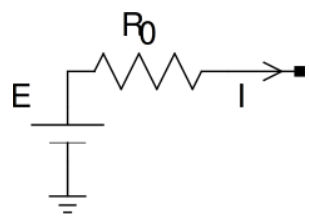

Fig. 7. Basic source used for comparison, $E$ is a low-pass filtered DC voltage. The small signal output impedance is given by $R_{0}$ and the output noise spectral density is $4 k_{B} T / R_{0}$.

The main disadvantage of this basic source compared to the proposed circuit is that if one wants to achieve the same output impedance for the same output current, a high value for $\mathrm{E}$ is then required. Taking values from table 1 for output impedance and current leads to $\mathrm{E}=20.4 \mathrm{kV}$ for instance.

For the two current sources, the same resistance was chosen: $R_{0}=10 \cdot R_{M}$. A low noise voltage differential amplifier was used to measure the voltage fluctuations either in the two-probe configuration (connected with the IP and IM pads) or in the four-probe configuration (connected with the VP and VM pads) as shown in figure 1. The spectral density of the voltage fluctuations was measured by using an Agilent 89410A spectrum analyzer.

As shown in figure 8, the spectra consist in white noise and $1 / \mathrm{f}$ noise at low frequency. White noise, mainly due to the contribution of the voltage amplifier and the voltage contact, is around $8 \times 10^{-17} \mathrm{~V}^{2} \cdot \mathrm{Hz}^{-1}$ for all the configurations.

Considering $1 / \mathrm{f}$ noise, the two-probe measurement level is more than 2 decades higher than the four-probe one. In the two-probe configuration, the $1 / \mathrm{f}$ noise level is dominated by the contribution of current contact indeed and the value of the spectral density $e_{n R C I}^{2}$ can be deduced.

In the four-probe configuration, the measurement with no current bias gives the intrinsic noise of the electronic read-out. As expected, the 1/f noise level increases when a DC current is applied. 


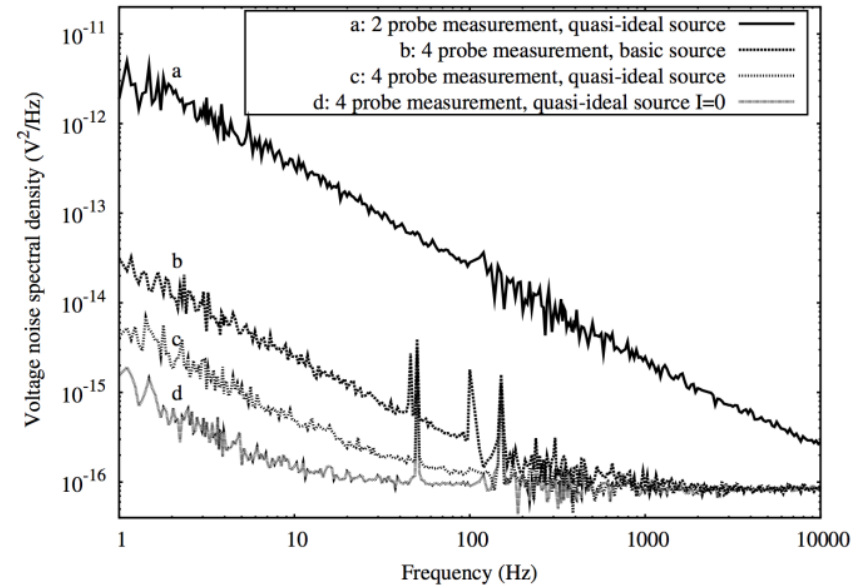

Fig. 8. Voltage noise spectral densities of one LSMO sample $\left(R_{M}=503 \Omega\right)$ measured with two different sources at the same current $I=581 \mu \mathrm{A}$. A basic one that consists in a filtered DC voltage source in series with a resistance $R_{0}$ and the quasi-ideal source. For each cases, the resistance $R_{0}$ is equal to $10 \times R_{M}$.

At $1 \mathrm{~Hz}$ and $I=581 \mu \mathrm{A}$, the noise level in the four-probe configuration is around $2.7 \times 10^{-14} \mathrm{~V}^{2} \cdot \mathrm{Hz}^{-1}$ and $4.9 \times 10^{-15} \mathrm{~V}^{2} \cdot \mathrm{Hz}^{-1}$ for the basic source and the quasi-ideal source respectively. To explain this difference, the different terms of (1) given the noise spectral density $e_{n V P V M}^{2}$ have been estimated with the different following assumptions and values: $e_{n M}^{2}$ given by the four-probe measurement with the quasi-ideal current source, $R_{M}=503 \Omega$, $R_{0}=4.99 \mathrm{k} \Omega$ and $R_{C I}=1.5 \mathrm{k} \Omega$ (deduced from the two-probe DC measurement). The results are reported in table 2 .

It is clear that the noise measured with the basic source is dominated by the current contact noise even with $R_{0}=$ $10 \cdot R_{M}$. In the case of the quasi-ideal source, both the contributions of the current source and the current contact are negligible. One should note that minimizing the current source noise can be easily achieved by increasing the resistance $R_{0}$ (but it then limits the maximum output current). One important point is clearly demonstrated here with a sample that exhibits a high level of contact noise: using a DC current source with a quasi-ideal output impedance allows deducing directly from one measurement and without any experimental or analytical corrections, the intrinsic noise of the material or device.

\section{TABLE II}

ESTIMATION OF THE DIFFERENT TERMS GIVEN THE NOISE SPECTRAL DENSITY $e_{n V P V M}^{2}$ AT F=1 HZ FOR THE BASIC SOURCE AND THE QUASI-IDEAL SOURCE PRESENTED IN THIS WORK

\begin{tabular}{|c|c|c|c|c|c|}
\hline & 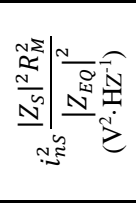 & 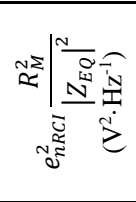 & 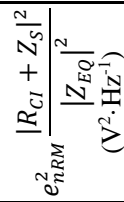 & 踣 & 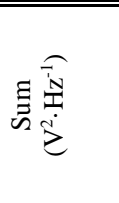 \\
\hline $\begin{array}{c}\text { Basic } \\
\text { source }\end{array}$ & $1.1 \times 10^{-17}$ & $2.0 \times 10^{-14}$ & $3.2 \times 10^{-15}$ & $1.1 \times 10^{-15}$ & $2.4 \times 10^{-14}$ \\
\hline $\begin{array}{l}\text { This } \\
\text { work }\end{array}$ & $2.0 \times 10^{-17}$ & $1.3 \times 10^{-22}$ & $3.8 \times 10^{-15}$ & $1.1 \times 10^{-15}$ & $4.9 \times 10^{-15}$ \\
\hline
\end{tabular}

Using the following numerical values:

$e_{n R M}^{2}=3.8 \times 10^{-15} \mathrm{~V}^{2} \cdot \mathrm{Hz}^{-1}$ (given by the four-probe measurement with the quasi-ideal current source), $e_{n R C I}^{2}=4 \times 10^{-12} \mathrm{~V}^{2} \cdot \mathrm{Hz}^{-1}$ (given by the 2 probe measurement with the quasi-ideal current source), $i_{n S}^{2}=8 \times 10^{-23} \mathrm{~A}^{2} \cdot \mathrm{Hz}^{-1}$, $R_{M}=503 \Omega, R_{0}=4.99 \mathrm{k} \Omega$ and $R_{C I}=1.5 \mathrm{k} \Omega$.

\section{CONCLUSION}

In this paper, a low noise and high output impedance DC current circuit has been presented. The overall performances in terms of DC output current, output impedance and noise are better than classical circuits. The proposed circuit has been used in a four-probe configuration dedicated to low frequency noise measurements. It has been shown that due to the high output impedance of the DC source, the current contact noise can be neglected and the intrinsic noise of the device under test can be estimated without any corrections, thus allowing confident low frequency noise measurements.

\section{ACKNOWLEDGMENT}

The authors want to thank Dalal Fadil, Jian Sun and Shuang Liu for useful electronic simulations; Benoit Renault, Sylvain Lebargy and Julien Gasnier for helpful technical realization.

\section{REFERENCES}

[1] F. Hooge, T. Kleinpenning and L.K.J. Vandamme, "Experimental studies on 1/f noise", Rep. Prog. Phys., 44, 741, 1981

[2] L. Méchin, F. Yang, J.M. Routoure, B. Guillet, S. Flament and D. Robbes, "Uncooled bolometer response of a low noise $\mathrm{La}_{2 / 3} \mathrm{Sr}_{1 / 3} \mathrm{MnO}_{3}$ thin film", Appl. Phys. Lett., 87, 204103, 2005

[3] I. Lartigau, J.M. Routoure, W. Guo, B. Cretu, R. Carin, A. Mercha, C. Claeys and E. Simoen, "Low temperature noise spectroscopy of $0.1 \mu \mathrm{m}$ partially depleted silicon on insulator metal-oxide-semiconductor field effect transistors", J. Appl. Phys, , 101,10, 104511, 2007

[4] W. Guo, B. Cretu, J.M. Routoure, R. Carin, E. Simoen, A. Mercha, N. Collaert, S. Put and C. Claeys, "Impact of strain and source/drain engineering on the low frequency noise behaviour in n-channel tri-gate FinFETs", Solid-State Electron., 52, 12, 1889, 2008

[5] M. Rzin, J.M. Routoure, B. Guillet, L. Méchin, M. Morales, C. Lacam, P. Gamarra, P. Ruterana, F. Medjdoub, "Impact of Gate-Drain Spacing on Low-Frequency Noise Performance of In Situ SiN Passivated InAlGaN/GaN MIS-HEMTs", IEEE Trans. Electron Devices, 64, 7, 2820, 2017

[6] C. Barone, G. Landi, C. Mauro, H.C. Neitzert and S. Pagano, "Universal crossover of the charge carrier fluctuation mechanism in different polymer/carbon nanotubes composites", Appl. Phys. Lett., 107, 14, 143106, 2015

[7] G. Landi, H.C. Neitzert, C. Barone, C. Mauro, F. Lang, S. Albrecht, B. Rech and S. Pagano, "Correlation between Electronic Defect States Distribution and Device Performance of Perovskite Solar Cells", Adv. Sci., 4, 10, 1700183, 2017

[8] A.S. Tucker, R.M. Fox and R.J. Sadleir, "Biocompatible, High Precision, Wideband, Improved Howland Current Source With Lead-Lag Compensation”, IEEE Trans. Biomed. Circuits Syst., 7, 1, 63, 2013

[9] R.A. Pease, "A Comprehensive Study of the Howland Current Pump", http://www.ti.com/li/an/snoa474a/snoa474a.pdf , 2008

[10] S.B. Ross, J.R. Davis and J. Dutra, "An extremely low noise, low cost, constant current supply”, Rev. Sci. Instrum., 64, 8, 2379, 1993

[11] S. Linzen, T.L. Robertson, T. Hime, B.L.T. Plourde, P.A. Reichardt and J. Clarke, "Low-noise computer-controlled current source for quantum coherence experiments", Rev. Sci. Instrum., 75, 8, 2541, 2004

[12] D. Talukdar, R. K. Chakraborty, S. Bose and K.K. Bardhan, "Low noise constant current source for bias dependent noise measurements", Rev. Sci. Instrum., 82, 1, 013906, 2011

[13] C. Ciofi, R. Giannetti, V. Dattilo and B Neri, "Ultra low-noise current sources", IEEE Trans. Instrum. Meas., 47, 1 78, 1998

[14] G. Scandurra, G. Cannatà, G. Giusi and C. Ciofi, "Programmable, very low noise current source", Rev. Sci. Instrum., 85, 125109, 2014

[15] G. Giusi, O. Giordano, G. Scandurra, C. Ciofi, M. Rapisasarda, and S. Calvi, "Automatic measurement system for the DC and low-f noise characterization of FETs at wafer level", IEEE Instrumentation and Measurement Technology Conference (IMTC) Proceedings (IEEE 2015), 2095 
[16] G. Giusi, O. Giordano, G. Scandurra, M. Rapisasarda, S. Calvi, and C. Ciofi, "High sensitivity measurement system for the direct-current, capacitance-voltage, and gate-drain low frequency noise characterization of field effect transistors", Rev. Sci. Instrum., 87, 044702, 2016

[17] C. Barone, A. Galdi, S. Pagano, O. Quaranta, L. Méchin, J.M. Routoure and P. Perna, "Experimental technique for reducing contact and background noise in voltage spectral density measurements", Rev. Sci. Instrum., 78, 093905, 2007

[18] F.N. Hooge, "1/f noise is no surface effect", Phys. Lett. A, 29, 3, 139, 1969

[19] F.N. Hooge and L.K.J. Vandamme, "Lattice scattering causes 1/f noise", Phys. Lett. A, 66, 4, 315, 1978

[20] C. Barone, S. Pagano, L. Méchin, J.M. Routoure, P. Orgiani and L. Maritato, "Apparent volume dependence of $1 / \mathrm{f}$ noise in thin film structures: Role of contacts", Rev. Sci. Instrum., 79, 053908, 2008

[21] G.R Mutta, J.M. Routoure, B. Guillet, L. Méchin, J. Grandal, S. Martin-Horcajo, T. Brazzini, F. Calle, M.A. Sanchez-Garcia, P. Marie and P. Ruterana, "Volume charge carrier number fluctuations probed by low frequency noise measurements in InN layers", Appl. Phys. Lett., 98, 252104,2011

[22] L. Méchin, S. Wu, B. Guillet, P. Perna, C. Fur, S. Lebargy, C. Adamo, D.G. Schlom, and J.M. Routoure, "Experimental evidence of correlation between 1/f noise level and metal-to-insulator transition temperature in epitaxial $\mathrm{La}_{0.7} \mathrm{Sr}_{0.3} \mathrm{MnO}_{3}$ thin films", J. Phys. D: Appl. Phys. - Fast Track Communication, 46, 202001, 2013

[23] A. Urushibara, Y. Moritomo, T. Arima, A. Asamitsu, G. Kido and Y. Tokura, "Insulator-metal transition and giant magnetoresistance in $\mathrm{La}_{1-\mathrm{x}}$ $\mathrm{Sr}_{\mathrm{x}} \mathrm{MnO}_{3}$ ", Phys. Rev. B, 51, 20, 14103, 1995

[24] A.M. Haghiri-Gosnet and J.P. Renard, "CMR manganites: physics, thin films and devices", J. Phys. D: Appl. Phys., 36, R127, 2003

[25] H.L. Liu, K.Y.J. Zhang, L.C. Wu, L. Uba, S. Uba, W.J. Chang, J.Y. Lin and L.M. Wang, "Optical and magneto-optical studies of $\left(\mathrm{La}_{0.7} \mathrm{~A}_{0.3}\right) \mathrm{MnO}_{3}$ $(\mathrm{A}=\mathrm{Sr}, \mathrm{Ca}$, and Ce) thin films", J. Magn. Magn. Mater., 304, 1, e303, 2006

[26] L. Méchin, J.M. Routoure, S. Mercone, F. Yang and S. Flament, "1/f noise in patterned $\mathrm{La}_{2 / 3} \mathrm{Sr}_{1 / 3} \mathrm{MnO}_{3}$ thin films in the 300 - $400 \mathrm{~K}$ range", $J$. Appl. Phys., 103, 083709, 2008

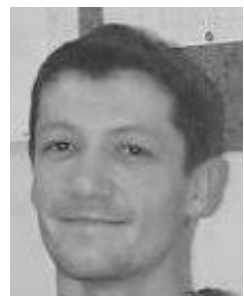

Jean-Marc Routoure received the Ph.D. degree in electronics from the University of Caen, France, in 1998. He joined the electronics team of the GREYC Laboratory in 2000 and he is currently a Professor with the University of Caen. He works on the low frequency noise of: integrated polysilicon resistors, Manganese oxides,

and advanced CMOS and III/V devices. His research interests include the metrology of noise measurements, the device physics and defect engineering in advanced devices with emphasis on the impact of the temperature on low frequency noise. He has authored or co-authored almost 100 papers in international journals and conferences. In 2013, he was the co-chairman of the International Conference on Noise and Fluctuations (ICNF) in Montpellier.

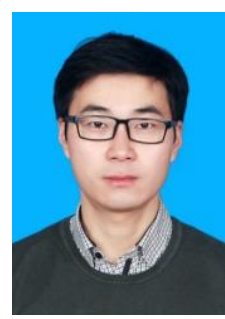

Sheng Wu received the $\mathrm{PhD}$ Degree in Microelectronics from the University of Caen, France, in 2012. He is doing postdoctoral research at Tianjin University, China. His research interests include magnetic alloy material, half-metallic material and their applications in the marine science fields. He is working on weak signal processing from underwater sensor and ocean monitoring network. He has authored or co-authored 16 publications in international journals and conferences.

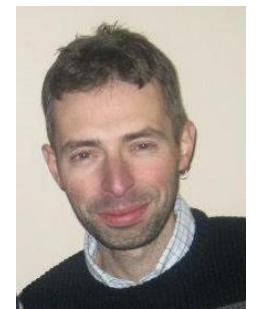

Carlo Barone received the PhD. Degree in Physics (specialization Condensed Matter) from the University of Salerno, Italy, in 2008. He is currently a research associate with the Physics Department of University of Salerno. From April 2017 he has the Habilitation for Associate Professor in Experimental Condensed Matter Physics. Most of his scientific and professional activity is focused on the elaboration of stochastic signals originated by non-equilibrium processes in innovative materials and devices He has authored or co-authored almost 50 papers in peer-review journals. From 2015, he is a member of the Editorial Board of Scientific Reports (a journal of Nature Publishing Group).

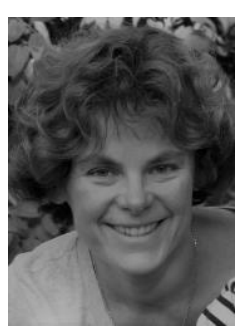

Laurence Méchin received the $\mathrm{PhD}$. Degree in electrical engineering from the University of Caen, France, in 1996. She is currently a CNRS Senior Scientist with GREYC, Caen, France. She has authored or co-authored more than 100 papers. Her research interests are the design, fabrication, and characterization of innovative materials such as functional oxides and nitrides for sensors and components.

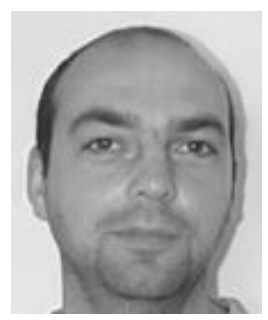

Bruno Guillet received the $\mathrm{PhD}$ and the accreditation to supervise research in Electronics-Microelectronics from the University of Caen, France, respectively in 2003 and in 2014. He is currently an associate professor in electronics with the University of Caen. His research interests include design, fabrication, and characterization of innovative materials such as functional oxides and nitrides for sensors and components. In GREYC laboratory, he is working on noise measurements, resistive thermometry and bolometers. He has authored or co-authored 35 publications in peer-review journals. 


\title{
A low noise and quasi-ideal DC current source dedicated to four-probe low frequency noise measurements
}

\author{
J.M. Routoure, S. Wu, C. Barone, L. Méchin, B. Guillet
}

\begin{abstract}
In this paper, a DC current source dedicated to four-probe low frequency noise measurements is presented. An output impedance value of $3 \mathrm{M} \Omega$ with a maximum output current of $1.5 \mathrm{~mA}$ was achieved. The white noise level of the current source was measured to be $4 \times 10^{-23} \mathrm{~A}^{2 \cdot} \cdot \mathbf{H z}^{-1}$ with a corner frequency of $30 \mathrm{~Hz}$. Thanks to its quasi-ideal behavior in terms of noise level and high output impedance value, this current source can be used to measure the intrinsic noise of materials using four-point measurements without any experimental or analytical corrections.
\end{abstract}

Index Terms-Low-frequency noise (LFN), DC current source, four-probe measurement

\section{INTRODUCTION}

$\mathrm{C}$ ompared to other classical techniques such as capacitance-voltage or deep level transient spectroscopy measurements, the $1 / \mathrm{f}$ low frequency noise measurements are one of the most sensitive tool to investigate material or device quality and performance [1]. For example, noise measurements allow to perform material comparison for sensor applications [2] or deep level spectroscopy on semiconductors devices [3], and to identify the impact of some technological steps or technologies on the degradation of device performances [4-7]. Despite all these advantages, one limitation of this technique is the difficulty to remove all the extrinsic low frequency noise sources to be sure that the measured noise comes only from the device or material under test. In the case of material characterization, it is well known that the four-probe configuration is adequate to remove contact contribution in DC and even white noise measurements. This is not the case for $1 / \mathrm{f}$ noise due to the possible noise contribution in voltage or current contacts.

Submission date: July 11, 2018

J.M. Routoure, B. Guillet and L. Méchin are with Normandie Univ, UNICAEN, ENSICAEN, CNRS, GREYC, 14000 Caen, France (e-mail: jean-marc.routoure@unicaen.fr, laurence.mechin@ensicaen.fr, and bruno.guillet@unicaen.fr).

$\mathrm{S}$. Wu was with Normandie Univ, UNICAEN, ENSICAEN, CNRS, GREYC, 14000 Caen, France. He is now with Tianjin University, 300072, China (e-mail: wusheng9201@ hotmail.com).

C. Barone is with the Dipartimento di Fisica "E.R. Caianiello" and CNR-SPIN, Università di Salerno, 84084 Fisciano, Salerno, Italy (email: cbarone@unisa.it).
In this paper we show that using a DC current source with both high output impedance value and moderate low frequency noise level in a four-probe configuration allows to obtain a direct measurement of the intrinsic noise sources of material without any experimental or analytical corrections (section II). The proposed circuit based on low noise operational amplifiers (OpAs) is described and compared with other current sources, operating in the low frequency range, found in literature (Section III). For the sake of clarity, here it is important to stress that other current source designs, having high output impedance, have been already developed for Electrical Impedance Tomography applications [8]. However, they are essentially dedicated to high frequency investigations and, therefore, do not cover the topic of this paper. The low noise characteristics of the proposed quasi-ideal DC current source, which looks like Howland current pump design [8], will be highlighted in this paper. In section IV, the performance of the proposed current source is demonstrated by measurements performed on a low noise material (namely $\mathrm{La}_{0.7} \mathrm{Sr}_{0.3} \mathrm{MnO}_{3}$ ) that exhibits a non-negligible contact noise contribution.

\section{FOUR- PROBE LOW FREQUENCY NOISE MEASUREMENTS}

The equivalent electrical circuit is presented in figure 1. First, four contact pads have to be realized on the sample. The DC current source is connected to two current pads (noted IP and IM) and DC or AC voltage is measured using two voltage pads (noted VP and VM, respectively). In this configuration, the sample electrical resistance $\mathrm{R}_{\mathrm{M}}$ can be deduced from the ratio between the measured voltage and the bias current, without any errors caused by the current and voltage contact resistances (noted $R_{C I}$ and $R_{C V}$, respectively). For simplicity, it is assumed that $R_{C I}\left(R_{C V}\right)$ is the sum of the current contact (voltage contact) resistances of the two probes IP and IM (VP and VM).

The voltage noise spectral density $e_{n V P V M}^{2}$ is the voltage noise measured at the voltage pads of the sample. It can be measured by a spectrum analyzer connected at the differential amplifier output that computes the output noise spectral density $e_{\text {nout }}^{2}$. Here, we assume that the frequencies are low enough to neglect all parasitic capacitances. For the differential amplifier, it is also considered that its input impedance is very high, its current noise can be neglected (with the choice of operational amplifiers based on FETs), and the voltage gain $\mathrm{K}$ is constant over all the frequency range of interest so that $e_{n V P V M}^{2}$ is directly given by $e_{\text {nOUT }}^{2} / K^{2}$. 


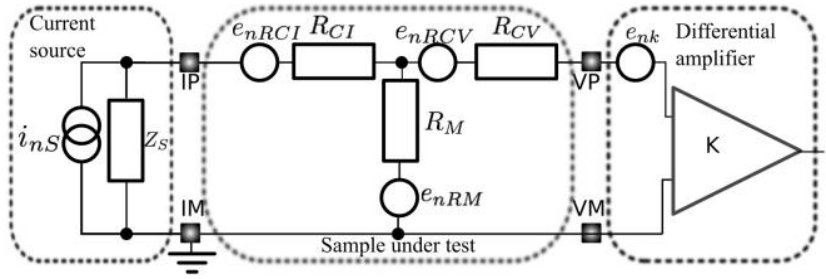

Fig. 1. Schematic representation of the four-probe technique showing the different elements of the circuit and the different noise sources. The resistance of the film under test is $R_{M}$. Its voltage noise is $e_{n R M} . R_{C I}$ and $R_{C V}$ are the current and voltage contact resistances, respectively. $e_{n R C I}$ and $e_{n R C V}$ are their associated voltage noise. The current source has an output impedance $Z_{S}$ and its current noise is $i_{n s}$. The voltage noise of the differential amplifier (of differential gain $K$ ) is $e_{n k}$. It is assumed that the current noise of the high input impedance differential amplifier can be neglected.

Each element introduces its own electrical noise, which may consist in white noise and excess noise. The following noise sources are related to the noise spectral densities:

- $e_{n R C I}$, the voltage noise spectral density of the current contact resistance,

- $e_{n R M}$, the voltage noise spectral density of the film,

- $e_{n R C V}$, the voltage noise spectral density of the voltage contact resistance,

- $e_{n k}$, the voltage noise spectral density of the differential amplifier.

In order to simplify the analysis, it will be assumed that the amplifier noise and the voltage contact noise can be neglected (in practice, these two contributions can be estimated when no DC current flows into the device and can be subtracted from all the measurement performed when a DC current is applied). Therefore, the noise spectral density $e_{n V P V M}^{2}$ at the differential amplifier input can be defined as:

$$
\begin{aligned}
e_{n V P V M}^{2}=\frac{e_{n O U T}^{2}}{K^{2}} & =e_{n R C I}^{2} \frac{R_{M}^{2}}{\left|Z_{E Q}\right|^{2}}+i_{n S}^{2} \frac{\left|Z_{S}\right|^{2} R_{M}^{2}}{\left|Z_{E Q}\right|^{2}} \\
& +e_{n R M}^{2} \frac{\left|R_{C I}+Z_{S}\right|^{2}}{\left|Z_{E Q}\right|^{2}}
\end{aligned}
$$

where

$$
\mathrm{Z}_{\mathrm{EQ}}=\mathrm{Z}_{\mathrm{S}}+\mathrm{R}_{\mathrm{CI}}+\mathrm{R}_{\mathrm{M}}
$$

The goal is the removal of all the extrinsic contributions and, consequently, the measurement of the intrinsic material noise. This can be obtained by choosing appropriate experimental conditions, so that the sample noise contribution dominates and the factor $\left|R_{C I}+Z_{S}\right|^{2} /\left|Z_{E Q}\right|^{2}$ equals unity. This could be achieved if the DC current source is ideal, i.e. if its output impedance $Z_{S}$ is infinite and its noise $i_{n S}$ is negligible. It can be shown that this is achieved if

$$
\text { and } \begin{gathered}
\left(\left|R_{C I}+Z_{S}\right| / R_{M}\right)^{2} \gg\left(e_{n R C I} / e_{n R M}\right)^{2} \\
i_{n S}^{2} \ll\left(e_{n R M} / R_{M}\right)^{2} \cdot\left|Z_{S}+R_{C I}\right|^{2} /\left|Z_{S}\right|^{2}
\end{gathered}
$$

Only an approximation of this ideal case can be reached. In practice, we will look for a quasi-ideal DC current source that exhibits the highest output impedance value as possible and the smallest noise level in the frequency range of interest.

Few publications dealing with the realization of quasi-ideal low noise DC current sources can be found and the proposed circuits are often dedicated to specific applications. In [9], the source allows to drive a stable and high current in magnetic coils. The proposed circuit is based on low noise OpAs associated with bipolar transistors: the maximum output current is $300 \mathrm{~mA}$, the output impedance can be evaluated to $10 \mathrm{M} \Omega$ and the white noise level is $6.3 \times 10^{-18} \mathrm{~A}^{2} \cdot \mathrm{Hz}^{-1}$ with a corner frequency of $1 \mathrm{~Hz}$ ( $c f$. table 1). In [10], the application consists in biasing a superconducting qubit with a long-term stability. The circuit consists in the classical representation of a DC current source: a well-controlled DC voltage source based on operational amplifiers in series with a constant metallic resistance: the output current is $275 \mu \mathrm{A}$, the output impedance is $10 \mathrm{k} \Omega$ and the white noise level is $0.7 \times 10^{-24} \mathrm{~A}^{2} \cdot \mathrm{Hz}^{-1}$ with a corner frequency of $100 \mathrm{~Hz}$. In order to measure low frequency noise, Talukdar et al. [11] and Ciofi et al. [12] have reported very low noise current sources based on JFET transistors, showing current noise densities of $10^{-22} \mathrm{~A}^{2} \cdot \mathrm{Hz}^{-1}$ with an output current of $10 \mathrm{~mA}$ and a corner frequency of $1 \mathrm{~Hz}$ and $3.5 \times 10^{-21}$ $\mathrm{A}^{2} \cdot \mathrm{Hz}^{-1}$ with an output current of $100 \mathrm{~mA}$ and a corner frequency of $1 \mathrm{~Hz}$, respectively. The output impedance values are not given but thanks to the JFET transistor datasheets, one can estimate an output impedance for these two references around $10 \mathrm{k} \Omega$. Scandurra et al. proposed also a programmable very low noise current source using a JFET device acting as high impedance current source and a MOSFET driver [13]. An automatic measurement system for direct-current, capacitance-voltage, and gate-drain low frequency noise characterization of field effect transistors using Source Measurement Units of a semiconductor parameter analyzer HP4155B has been reported [14, 15]. Finally, the more recent and complete description of a four-probe setup can be found in [16]. In this paper, a basic DC current source that consists in a filtered DC voltage in series with a metallic resistance is used. The output impedance is given by the resistance value used and the white noise level by its thermal noise. Due to the non-ideality of the current source, two measurements are required, one in the four-probe configuration and the other in the two probe configuration (when the differential amplifier is connected to the IP and IM pads). Moreover, the analysis needs numerical corrections to remove all the extrinsic noise contributions.

\section{THE LOW NOISE HIGH OUTPUT IMPEDANCE DC CURRENT SOURCE}

\section{A. Circuit design and DC output current}

The schematic of the proposed circuit for a low noise high output impedance DC source is given in figure 2. The source is 


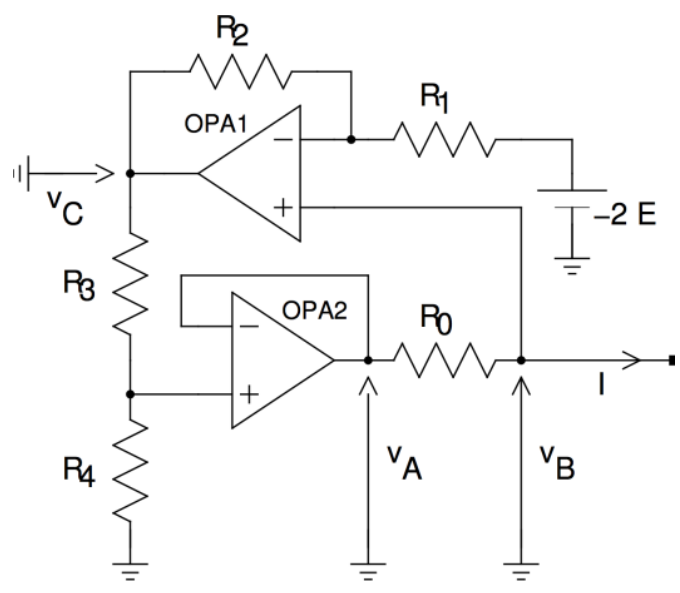

Fig. 2. Schematic of the proposed DC current source circuit. If resistance $R_{1}$ to $R_{4}$ are equal, the circuit ensures that $v_{A}=v_{B}+E$. The resistance $R_{0}$ sets the output current DC value, the small signal output impedance and the noise performance.

built using two low noise OpAs and several resistances. The first OpA acts as a summing-subtracting amplifier whereas the second one is a simple follower. The purpose of the circuit is to measure the voltage $v_{B}$ and to add an external DC voltage $2 E$ so that the voltage $v_{A}$ is equal to $v_{B}+E$. This is achieved if $R_{1}=R_{2}$ and $R_{3}=R_{4}$.

Assuming that the OpAs are ideal and that the four electrical resistances are equal, the output current I in $R_{0}$ is given by:

$$
I=\frac{v_{A}-v_{B}}{R_{0}}=\frac{E}{R_{0}}
$$

The DC output current is limited by the saturation voltage $\mathrm{V}_{\mathrm{SAT}}$ of the first OpA (named as OPA1). Since $v_{C}=2 v_{B}+2 E$, assuming that the biased device is an electrical resistance $R_{M}$ $\left(v_{B}=R_{M} \cdot I\right)$, it can be shown using previous equation that:

$$
|I| \ll \frac{\left|V_{S A T}\right|}{2\left(R_{M}+R_{0}\right)}
$$

The maximum output current $I_{\text {OUT }}$ is found to be about $6.8 \mathrm{~mA}$ for $R_{0}=1 \mathrm{k} \Omega=10 \cdot R_{M}$ and $V_{S A T}=15 \mathrm{~V}$. For smaller values of $R_{0}$, the current limitation is due to the OpAs (and can be as high as about $20 \mathrm{~mA}$ ).

\section{B. Small signal output impedance}

In order to predict the small signal output impedance value, one has to take into account the open-loop gain $A_{D}$ of the OpAs and the fact that the condition $R_{I}=R_{2}=R_{3}=R_{4}$ can only be approximated in practice. A first-order low-pass filter approximation for the OpA open-loop gain $A_{D}$ is used $\left(A_{D}=\right.$ $A_{D 0} /\left(1+j \cdot \frac{f}{f_{0}}\right)$ ).

We also introduce the parameters $\alpha$ and $\varepsilon$ to model the small mismatches between the four real electrical resistances in the real circuit. These parameters are defined by $R_{1}=\alpha \cdot R_{2}$ and $R_{3}=(\alpha+\varepsilon) \cdot R_{4}$. The parameter $\alpha$ models the quasi equality between the four resistances and the whole mismatch between these resistances can be written using only $\varepsilon$. The four resistances have been chosen to be as identical as possible so that $\alpha=1$ and $\varepsilon \sim 0$. One can finally express the small signal output impedance $Z_{S}$ by:

$$
Z_{S}=\left(\frac{(1+\alpha)+(1+\alpha+\varepsilon)(1+\alpha) A_{D}+(1+\varepsilon) A_{D}^{2}}{(1+\alpha)+(1+\alpha+\varepsilon)(1+\alpha) A_{D}+\varepsilon A_{D}^{2}}\right) \cdot R_{0}
$$

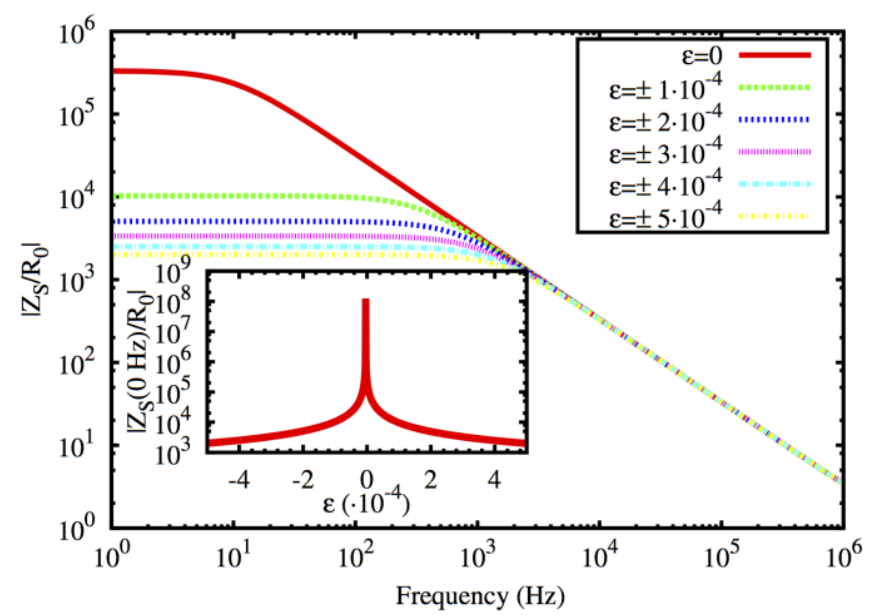

Fig. 3. Magnitude of the output impedance $\left|Z_{S} / R_{0}\right|$ versus frequency for different values of the mismatch $\varepsilon$ between $R_{3}$ and $R_{4}$. A first order low pass behavior of $Z_{S}$ is obtained. Inset shows the DC output impedance versus $\varepsilon$.

It shows that the output impedance is proportional to $R_{0}$. In order to investigate the output impedance variations with the mismatches in the resistance values, the calculated values of the output impedance $\left|Z_{S} / R_{0}\right|$ are plotted in figure 3 versus frequency for several $\varepsilon$ values close to 0 . The inset shows the DC value versus $\varepsilon$. For this calculation, classical values for standard OpAs have been assumed (i.e., $A_{D 0}=10^{6}$ and $f_{0}=$ $10 \mathrm{~Hz}$ ).

These calculations show that only a discrete value of $\varepsilon$ very close to 0 allows to obtain a DC output impedance almost equal to $10^{5}$ times the resistance $R_{0}$, otherwise a more reasonable factor of about $10^{3}$ is obtained. Figure 4 shows that the output impedance decreases with increasing frequency with a slope close to $20 \mathrm{~dB}$ per decade due to the frequency response of the OpA. A compromise needs to be done between high value of the output impedance and the range of frequencies for which these high values are obtained.

In practice, when using resistances with very low temperature coefficient, a low mismatch of less than $5 \times 10^{-4}$ between resistance values could be easily achieved. The current source output impedance $\left|Z_{S}\right|$ is therefore expected to be at least $10^{3}$ times the value of $R_{0}$ at low frequency (up to around one $\mathrm{kHz}$ ). This is demonstrated in figure 4 that shows the measured output impedance versus frequency. Transfer-function measurements using sweep mode of spectrum analyzer as excitation signals instead of the DC voltage $2 E$ have been used to estimate the output impedance. The ratio of two transfer functions with two different fixed 
electrical resistor $R_{M}$ value ( $10 \mathrm{k} \Omega$ and $100 \mathrm{k} \Omega$ ) enable the $Z_{S}(f)$ estimation.

The proposed model is also plotted and a very good agreement is found between measurements and theory: as expected, the output impedance is, at low frequency, proportional to $R_{0}$ with a factor higher than one thousand. A first order behavior is also obtained at intermediate frequency as predicted. The comparison between measurements and model is consistent with a value of $\varepsilon$ around $3 \times 10^{-4}$ in the realized circuit. Deviation between the model and the measurements at highest frequencies may be due to the simple first-order low pass filter model used for the frequency response of the OpAs.

Finally, with this mismatch value, the output impedance is at least one thousand time the resistance $R_{0}$ at frequencies up to few hundred $\mathrm{Hz}$.

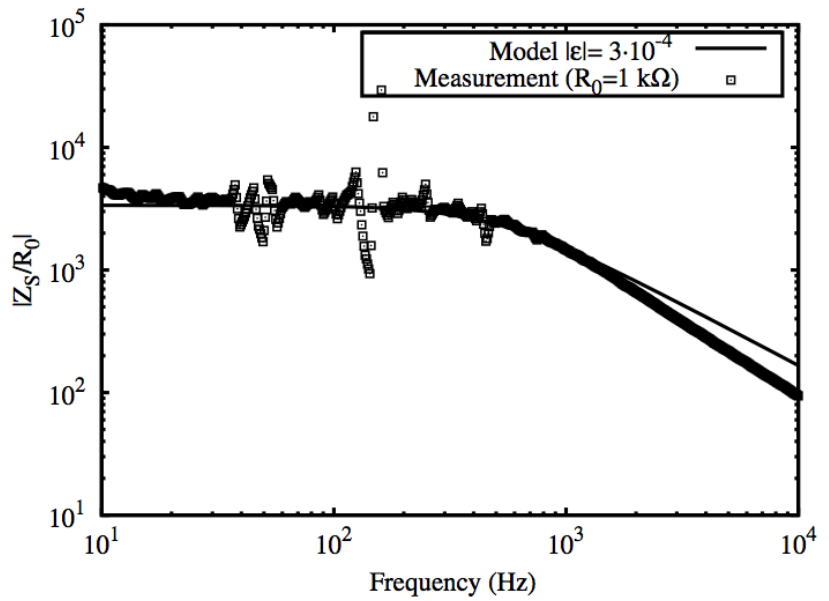

Fig. 4. Small signal output impedance $Z_{S}$ divided by $R_{0}$. Comparison between measurements and model for $R_{0}=1 \mathrm{k} \Omega$. In the realized circuit, the mismatch between resistances must be close to $3 \times 10^{-4}$.

\section{Noise level}

The noise of the current source is due to the thermal noise of each resistance (of spectral density $e_{n R i}^{2}$ ) and to the equivalent voltage noise of the two OpAs (of spectral densities $e_{n A}^{2}$ and $e_{n B}^{2}$ ). Due to the small resistance values connected at the input of the OpAs, the equivalent current noise can be neglected. To ensure that this assumption is verified, JFET based OpAs (AD 743) has been used in the realized circuit.

The noise of the external voltage source is also neglected here because in practice, this external voltage can be generated either by batteries or by a filtered voltage source using a very low frequency low-pass filter. Assuming $R_{1}=R_{2}=$ $R_{3}=R_{4}=R$, the current white noise spectral density $i_{n s}^{2}$ of the source is given by:

$i_{n S}^{2}=\frac{4 k_{B} T}{R_{0}}+\frac{4 k_{B} T R+e_{n A}^{2}+e_{n B}^{2}}{R_{0}^{2}}$

with $k_{B}=1.38 \times 10^{-23} \mathrm{~J} \cdot \mathrm{K}^{-1}$ the Boltzmann constant and $T$ the temperature in kelvin. The measured current noise spectral density $i_{n s}^{2}$ of the current source is plotted in figure 5 for three values of $R_{0}$ and $R=464 \Omega$. Only white noise is observed for $R_{0}=100 \mathrm{k} \Omega$, whereas, the low frequency noise of the OpAs has to be taken into account for $R_{0}=1 \mathrm{k} \Omega$ and $10 \mathrm{k} \Omega$.

The measured white noise level as well as its expected value are plotted in the inset of figure 5 and show a very good agreement in the realized circuit $\left(e_{n A}^{2}+e_{n B}^{2}+4 \cdot k_{B} \cdot T\right.$. $\left.R=25 \times 10^{-18} \mathrm{~V}^{2} \cdot \mathrm{Hz}^{-1}\right)$. When $R_{0}$ is higher than $1.5 \mathrm{k} \Omega$, the current source white noise is dominated by the thermal noise of the resistance $R_{0}$.

The low frequency noise is due to the OpAs and its contribution decreases with $R_{0}^{2}$. Therefore, the current source low frequency noise almost disappears when $R_{0}$ is higher than $10 \mathrm{k} \Omega$. With $R_{0}=1 \mathrm{k} \Omega, i_{n S}^{2}=2 \times 10^{-21} \mathrm{~A}^{2} \cdot \mathrm{Hz}^{-1}$ at $1 \mathrm{~Hz}$.

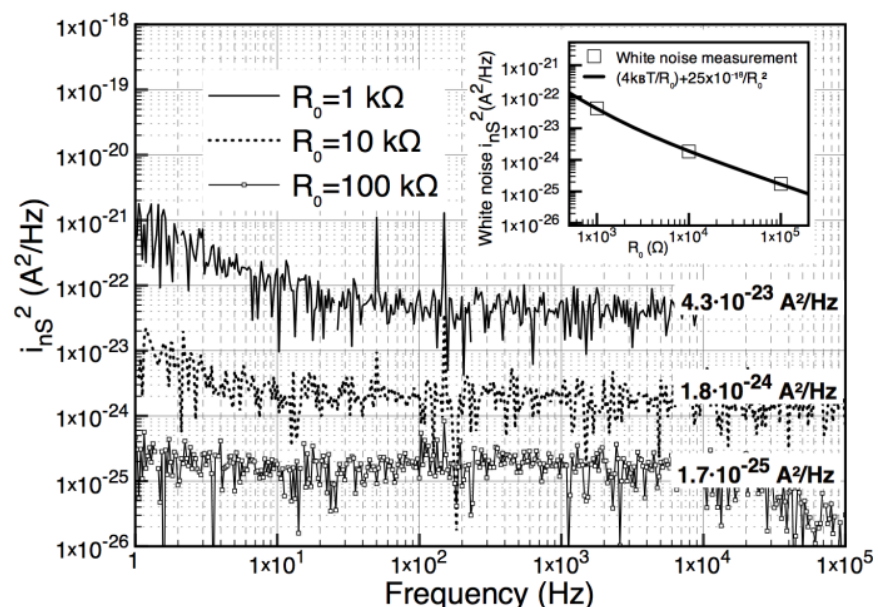

Fig. 5. Measured current noise spectral density $i_{n s}^{2}$ of the current source for three values of the resistance $R_{0}$. Except for $R_{0}=1 \mathrm{k} \Omega$, mostly white noise is measured. Numerical values of the white noise level are indicated for each value of $R_{0}$. Inset shows the good agreement between the measured white noise spectral density and its expected values.

Finally, for $R_{0}=1 \mathrm{k} \Omega$ (values of $R_{0}$ that gives almost the highest output current with reasonable low noise performance) the maximum output current is $1.5 \mathrm{~mA}$, the output impedance can be estimated around $3 \mathrm{M} \Omega$ below $1 \mathrm{kHz}$ and the noise level is $4 \times 10^{-23} \mathrm{~A}^{2} \mathrm{~Hz}^{-1}$ with a corner frequency of $10 \mathrm{~Hz}$. These values are summarized in table I.

The voltage noise spectral density $e_{n V P V M}^{2}$ is the voltage noise measured at the voltage pads of the sample. It can be measured by a spectrum analyzer connected at the differential amplifier output that computes the output noise spectral density $e_{\text {nouT }}^{2}$. Here, we assume that the frequencies are low enough to neglect all parasitic capacitances. For the differential amplifier, it is also considered that its input impedance is very high, its current noise can be neglected (with the choice of operational amplifiers based on FETs), and the voltage gain $\mathrm{K}$ is constant over all the frequency range of interest so that $e_{n V P V M}^{2}$ is directly given by $e_{\text {nOUT }}^{2} / K^{2}$. 
TABLE I

SUMMARY OF PUBLISHED DC CURRENT SOURCE CHARACTERISTICS

\begin{tabular}{c|c|c|c|c}
\hline \hline Reference & $\begin{array}{c}\text { Maximum } \\
\text { output } \\
\text { current } \\
(\mathrm{mA})\end{array}$ & $\begin{array}{c}\text { Output } \\
\text { impedance } \\
(\Omega)\end{array}$ & $\begin{array}{c}\text { White } \\
\text { noise level } \\
\left(\mathrm{A}^{2} \cdot \mathrm{Hz}^{-1}\right)\end{array}$ & $\begin{array}{c}\text { Corner } \\
\text { frequency } \\
(\mathrm{Hz})\end{array}$ \\
\hline $\begin{array}{c}\text { Ross } \text { et al. } \\
{[9]}\end{array}$ & 300 & $10 \mathrm{M} \Omega$ & $6.3 \times 10^{-18}$ & 1 \\
$\begin{array}{c}\text { Linzen } \text { et al. } \\
{[10]}\end{array}$ & 0.275 & $10 \mathrm{k} \Omega$ & $0.7 \times 10^{-24}$ & 100 \\
$\begin{array}{c}\text { Talukdar } \text { et al. } \\
{[11]} \\
\begin{array}{c}\text { Ciofi } \text { et al. } \\
{[12]} \\
\text { This work }\end{array}\end{array}$ & 10 & $\sim 10 \mathrm{k} \Omega$ & $1 \times 10^{-22}$ & 1 \\
\hline \hline
\end{tabular}

${ }^{\mathrm{a}}$ for $R_{0}=1 \mathrm{k} \Omega$
${ }^{\mathrm{b}}$ below $1 \mathrm{kHz}$

\section{Conclusion}

Table 1 summarizes and compares the maximum output current, the output impedance, the white noise level and the corner frequency of different published DC current sources. It is clear that a universal circuit with optimal characteristics, i.e. low noise, high output impedance and high maximum current does not exist. Best results in terms of noise (especially at low frequency) and maximum output current have been obtained with JFET based circuits but the output impedance is then rather small and not suitable for low frequency noise four-probe measurement. On the contrary, the use of OpAs leads to high output impedance value but it also exhibits higher noise level [9]. The proposed circuit is not the best one in case of noise performances and maximum output current but it is the only one that exhibits both a high output impedance with a sufficiently low noise level with a reasonable maximum output current. In the next section, it will be shown that these performances are optimum to measure intrinsic low frequency noise of material without any corrections.

\section{EXPERIMENTAL VALIDATION}

This low noise current source has been developed in the framework of low frequency noise characterization of different materials [16-21]. In order to demonstrate the improved performances of the source, some results measured in $\mathrm{La}_{0.7} \mathrm{Sr}_{0.3} \mathrm{MnO}_{3}$ (LSMO) thin films deposited onto $\mathrm{SrTiO}_{3}$ substrates are shown. This kind of sample exhibits several interesting properties both for theoretical or application point of views and has been strongly studied over the last decades [2, 22-25]. Sample fabrication details can be found in [25].

It has also been previously shown that this kind of sample exhibits a high level of the current contact noise [16]. The film thickness is $150 \mathrm{~nm}$, the width and the length of the devices which act as a simple resistance are $100 \mu \mathrm{m}$ and $150 \mu \mathrm{m}$, respectively. They were patterned so that two current pads and two voltage pads are available. Finally, the LSMO sample exhibits an electrical resistance value $R_{M}=503 \Omega$.
Two current sources were used to bias the device with the same DC current: the source described in the previous section and the "classical" one with a low-pass filtered DC voltage in series with a resistance named $R_{0}$ ("basic source") shown in figure 6 .

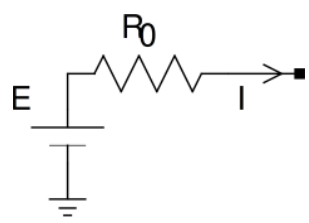

Fig. 6. Basic source used for comparison, $E$ is a low-pass filtered DC voltage. The small signal output impedance is given by $R_{0}$ and the output noise spectral density is $4 k_{B} T / R_{0}$.

The main disadvantage of this basic source compared to the proposed circuit is that if one wants to achieve the same output impedance for the same output current, a high value for $\mathrm{E}$ is then required. Taking values from table 1 for output impedance and current leads to $\mathrm{E}=20.4 \mathrm{kV}$ for instance.

For the two current sources, the same resistance was chosen: $R_{0}=10 \cdot R_{M}$. A low noise voltage differential amplifier was used to measure the voltage fluctuations either in the two-probe configuration (connected with the IP and IM pads) or in the four-probe configuration (connected with the VP and VM pads) as shown in figure 1 . The spectral density of the voltage fluctuations was measured by using an Agilent 89410A spectrum analyzer.

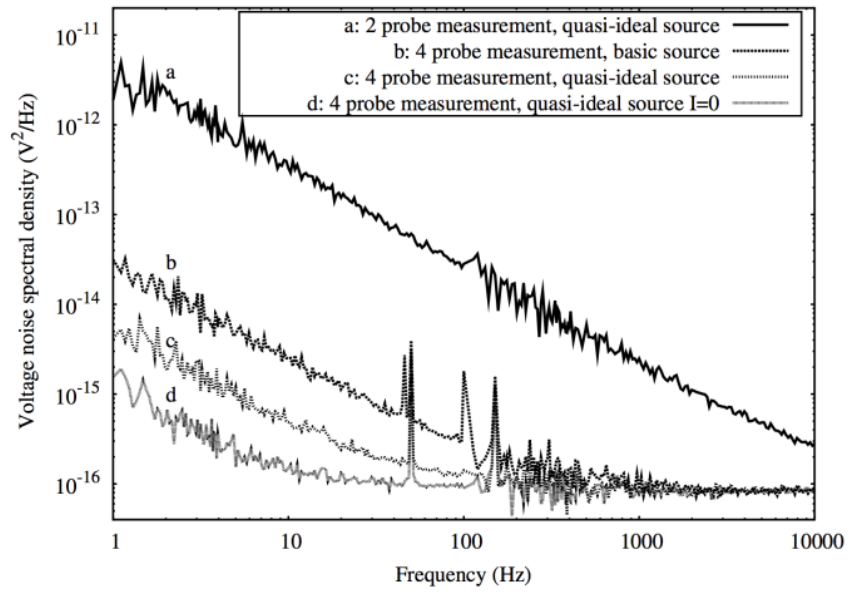

Fig. 7. Voltage noise spectral densities of one LSMO sample $\left(R_{M}=503 \Omega\right)$ measured with two different sources at the same current $I=581 \mu \mathrm{A}$. A basic one that consists in a filtered DC voltage source in series with a resistance $R_{0}$ and the quasi-ideal source. For each cases, the resistance $R_{0}$ is equal to $10 \times R_{M}$.

As shown in figure 7, the spectra consist in white noise and $1 / \mathrm{f}$ noise at low frequency. White noise, mainly due to the contribution of the voltage amplifier and the voltage contact, is around $8 \times 10^{-17} \mathrm{~V}^{2} \cdot \mathrm{Hz}^{-1}$ for all the configurations.

Considering $1 / \mathrm{f}$ noise, the two-probe measurement level is more than 2 decades higher than the four-probe one. In the two-probe configuration, the $1 / \mathrm{f}$ noise level is dominated by the contribution of current contact indeed and the value of the spectral density $e_{n R C I}^{2}$ can be deduced. 
TABLE II

NUMERICAL ESTIMATION OF THE DIFFERENT TERMS GIVEN THE NOISE SPECTRAL DENSITY $e_{n V P V M}^{2}$ AT F=1 HZ FOR THE BASIC SOURCE AND THE QUASI-IDEAL SOURCE PRESENTED IN THIS WORK

\begin{tabular}{|c|c|c|c|c|c|}
\hline & 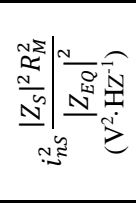 & 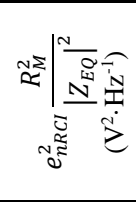 & 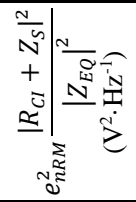 & 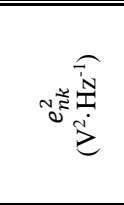 & 站突 \\
\hline $\begin{array}{c}\text { Basic } \\
\text { source }\end{array}$ & $1.1 \times 10^{-17}$ & $2.0 \times 10^{-14}$ & $3.2 \times 10^{-15}$ & $1.1 \times 10^{-15}$ & $2.4 \times 10^{-14}$ \\
\hline $\begin{array}{l}\text { This } \\
\text { work }\end{array}$ & $2.0 \times 10^{-17}$ & $1.3 \times 10^{-22}$ & $3.8 \times 10^{-15}$ & $1.1 \times 10^{-15}$ & $4.9 \times 10^{-15}$ \\
\hline
\end{tabular}

Using the following numerical values:

$e_{n R M}^{2}=3.8 \times 10^{-15} \mathrm{~V}^{2} \cdot \mathrm{Hz}^{-1}$ (given by the four-probe measurement with the quasi-ideal current source), $e_{n R C I}^{2}=4 \times 10^{-12} \mathrm{~V}^{2} \cdot \mathrm{Hz}^{-1}$ (given by the 2 probe measurement with the quasi-ideal current source), $i_{n s}^{2}=8 \times 10^{-23} \mathrm{~A}^{2} \cdot \mathrm{Hz}^{-1}$, $R_{M}=503 \Omega, R_{0}=4.99 \mathrm{k} \Omega$ and $R_{C I}=1.5 \mathrm{k} \Omega$.

In the four-probe configuration, the measurement with no current bias gives the intrinsic noise of the electronic read-out. As expected, the 1/f noise level increases when a DC current is applied.

At $1 \mathrm{~Hz}$ and $I=581 \mu \mathrm{A}$, the noise level in the four-probe configuration is around $2.7 \times 10^{-14} \mathrm{~V}^{2} \cdot \mathrm{Hz}^{-1}$ and $4.9 \times 10^{-15} \mathrm{~V}^{2} \cdot \mathrm{Hz}^{-1}$ for the basic source and the quasi-ideal source respectively. To explain this difference, the different terms of (1) given the noise spectral density $e_{n V P V M}^{2}$ have been estimated with the different following assumptions and values: $e_{n M}^{2}$ given by the four-probe measurement with the quasi-ideal current source, $R_{M}=503 \Omega$, $R_{0}=4.99 \mathrm{k} \Omega$ and $R_{C I}=1.5 \mathrm{k} \Omega$ (deduced from the two-probe DC measurement). The results are reported in table 2 .

It is clear that the noise measured with the basic source is dominated by the current contact noise even with $R_{0}=$ $10 \cdot R_{M}$. In the case of the quasi-ideal source, both the contributions of the current source and the current contact are negligible. One should note that minimizing the current source noise can be easily achieved by increasing the resistance $R_{0}$ (but it then limits the maximum output current). One important point is clearly demonstrated here with a sample that exhibits a high level of contact noise: using a DC current source with a quasi-ideal output impedance allows deducing directly from one measurement and without any experimental or analytical corrections, the intrinsic noise of the material or device.

\section{CONCLUSION}

In this paper, a low noise and high output impedance DC current circuit has been presented. The overall performances in terms of DC output current, output impedance and noise are better than classical circuits. The proposed circuit has been used in a four-probe configuration dedicated to low frequency noise measurements. It has been shown that due to the high output impedance of the DC source, the current contact noise can be neglected and the intrinsic noise of the device under test can be estimated without any corrections, thus allowing confident low frequency noise measurements.

\section{ACKNOWLEDGMENT}

The authors want to thank Dalal Fadil, Jian Sun and Shuang Liu for useful electronic simulations; Benoit Renault, Sylvain Lebargy and Julien Gasnier for helpful technical realization.

\section{REFERENCES}

[1] F. Hooge, T. Kleinpenning and L.K.J. Vandamme, "Experimental studies on 1/f noise", Rep. Prog. Phys., 44, 741, 1981

[2] L. Méchin, F. Yang, J.M. Routoure, B. Guillet, S. Flament and D. Robbes, "Uncooled bolometer response of a low noise $\mathrm{La}_{2 / 3} \mathrm{Sr}_{1 / 3} \mathrm{MnO}_{3}$ thin film", Appl. Phys. Lett., 87, 204103, 2005

[3] I. Lartigau, J.M. Routoure, W. Guo, B. Cretu, R. Carin, A. Mercha, C. Claeys and E. Simoen, "Low temperature noise spectroscopy of $0.1 \mu \mathrm{m}$ partially depleted silicon on insulator metal-oxide-semiconductor field effect transistors", J. Appl. Phys, , 101,10, 104511, 2007

[4] W. Guo, B. Cretu, J.M. Routoure, R. Carin, E. Simoen, A. Mercha, N. Collaert, S. Put and C. Claeys, "Impact of strain and source/drain engineering on the low frequency noise behaviour in n-channel tri-gate FinFETs", Solid-State Electron., 52, 12, 1889, 2008

[5] M. Rzin, J.M. Routoure, B. Guillet, L. Méchin, M. Morales, C. Lacam, P. Gamarra, P. Ruterana, F. Medjdoub, "Impact of Gate-Drain Spacing on Low-Frequency Noise Performance of In Situ SiN Passivated InAlGaN/GaN MIS-HEMTs", IEEE Trans. Electron Devices, 64, 7, 2820,2017

[6] C. Barone, G. Landi, C. Mauro, H.C. Neitzert and S. Pagano, "Universal crossover of the charge carrier fluctuation mechanism in different polymer/carbon nanotubes composites", Appl. Phys. Lett., 107, 14, 143106, 2015

[7] G. Landi, H.C. Neitzert, C. Barone, C. Mauro, F. Lang, S. Albrecht, B. Rech and S. Pagano, "Correlation between Electronic Defect States Distribution and Device Performance of Perovskite Solar Cells", Adv. Sci., 4, 10, 1700183, 2017

[8] A.S. Tucker, R.M. Fox and R.J. Sadleir, "Biocompatible, High Precision, Wideband, Improved Howland Current Source With Lead-Lag Compensation", IEEE Trans. Biomed. Circuits Syst., 7, 1, 63, 2013 ; R.A. Pease, "A Comprehensive Study of the Howland Current Pump", http://www.ti.com/li/an/snoa474a/snoa474a.pdf , 2008

[9] S.B. Ross, J.R. Davis and J. Dutra, "An extremely low noise, low cost, constant current supply", Rev. Sci. Instrum., 64, 8, 2379, 1993

[10] S. Linzen, T.L. Robertson, T. Hime, B.L.T. Plourde, P.A. Reichardt and J. Clarke, "Low-noise computer-controlled current source for quantum coherence experiments", Rev. Sci. Instrum., 75, 8, 2541, 2004

[11] D. Talukdar, R. K. Chakraborty, S. Bose and K.K. Bardhan, "Low noise constant current source for bias dependent noise measurements", Rev. Sci. Instrum., 82, 1, 013906, 2011

[12] C. Ciofi, R. Giannetti, V. Dattilo and B Neri, "Ultra low-noise current sources", IEEE Trans. Instrum. Meas., 47, 1 78, 1998

[13] G. Scandurra, G. Cannatà, G. Giusi and C. Ciofi, "Programmable, very low noise current source", Rev. Sci. Instrum., 85, 125109, 2014

[14] G. Giusi, O. Giordano, G. Scandurra, C. Ciofi, M. Rapisasarda, and S. Calvi, "Automatic measurement system for the DC and low-f noise characterization of FETs at wafer level", IEEE Instrumentation and Measurement Technology Conference (IMTC) Proceedings (IEEE 2015), 2095

[15] G. Giusi, O. Giordano, G. Scandurra, M. Rapisasarda, S. Calvi, and C. Ciofi, "High sensitivity measurement system for the direct-current, capacitance-voltage, and gate-drain low frequency noise characterization of field effect transistors", Rev. Sci. Instrum., 87, 044702, 2016

[16] C. Barone, A. Galdi, S. Pagano, O. Quaranta, L. Méchin, J.M. Routoure and P. Perna, "Experimental technique for reducing contact and background noise in voltage spectral density measurements", Rev. Sci. Instrum., 78, 093905, 2007

[17] F.N. Hooge, "1/f noise is no surface effect", Phys. Lett. A, 29, 3, 139, 1969

[18] F.N. Hooge and L.K.J. Vandamme, "Lattice scattering causes 1/f noise", Phys. Lett. A, 66, 4, 315, 1978

[19] C. Barone, S. Pagano, L. Méchin, J.M. Routoure, P. Orgiani and L. Maritato, "Apparent volume dependence of $1 / \mathrm{f}$ noise in thin film structures: Role of contacts", Rev. Sci. Instrum., 79, 053908, 2008

[20] G.R Mutta, J.M. Routoure, B. Guillet, L. Méchin, J. Grandal, S. Martin-Horcajo, T. Brazzini, F. Calle, M.A. Sanchez-Garcia, P. Marie 
and P. Ruterana, "Volume charge carrier number fluctuations probed by low frequency noise measurements in InN layers", Appl. Phys. Lett., 98, 252104, 2011

[21] L. Méchin, S. Wu, B. Guillet, P. Perna, C. Fur, S. Lebargy, C. Adamo, D.G. Schlom, and J.M. Routoure, "Experimental evidence of correlation between 1/f noise level and metal-to-insulator transition temperature in epitaxial $\mathrm{La}_{0.7} \mathrm{Sr}_{0.3} \mathrm{MnO}_{3}$ thin films", J. Phys. D: Appl. Phys. - Fast Track Communication, 46, 202001, 2013

[22] A. Urushibara, Y. Moritomo, T. Arima, A. Asamitsu, G. Kido and Y. Tokura, "Insulator-metal transition and giant magnetoresistance in $\mathrm{La}_{1-\mathrm{x}}$ $\mathrm{Sr}_{\mathrm{x}} \mathrm{MnO}_{3}$ ”, Phys. Rev. B, 51, 20, 14103, 1995

[23] A.M. Haghiri-Gosnet and J.P. Renard, "CMR manganites: physics, thin films and devices", J. Phys. D: Appl. Phys., 36, R127, 2003

[24] H.L. Liu, K.Y.J. Zhang, L.C. Wu, L. Uba, S. Uba, W.J. Chang, J.Y. Lin and L.M. Wang, "Optical and magneto-optical studies of $\left(\mathrm{La}_{0.7} \mathrm{~A}_{0.3}\right) \mathrm{MnO}_{3}$ $(\mathrm{A}=\mathrm{Sr}, \mathrm{Ca}$, and Ce) thin films", J. Magn. Magn. Mater., 304, 1, e303, 2006

[25] L. Méchin, J.M. Routoure, S. Mercone, F. Yang and S. Flament, "1/f noise in patterned $\mathrm{La}_{2 / 3} \mathrm{Sr}_{1 / 3} \mathrm{MnO}_{3}$ thin films in the 300 - $400 \mathrm{~K}$ range", $J$. Appl. Phys., 103, 083709, 2008

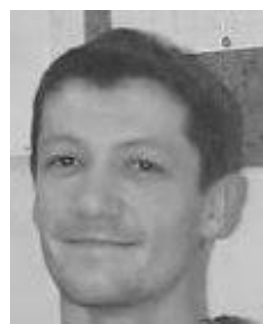

Jean-Marc Routoure received the $\mathrm{Ph} . \mathrm{D}$. degree in electronics from the University of Caen, France, in 1998. He joined the electronics team of the GREYC Laboratory in 2000 and he is currently a Professor with the University of Caen. He works on the low frequency noise of: integrated polysilicon resistors, Manganese oxide compounds, and advanced CMOS and III/V devices. His research interests include the metrology of noise measurements, the device physics and defect engineering in advanced devices with emphasis on the impact of the temperature on low frequency noise. He has authored or co-authored almost 100 papers in international journals and conferences. In 2013, he was the co-chairman of the International Conference on Noise and Fluctuations (ICNF) in Montpellier.

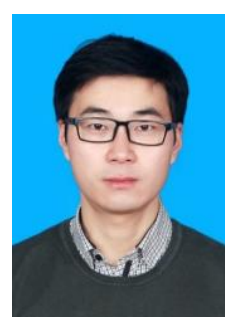

Sheng Wu received the $\mathrm{PhD}$ Degree in Microelectronics from the University of Caen, France, in 2012. He is doing postdoctoral research at Tianjin University, China. His research interests include magnetic alloy material, half-metallic material and their applications in the marine science fields. He is working on weak signal processing from underwater sensor and ocean monitoring network. He has authored or co-authored 16 publications in international journals and conferences.

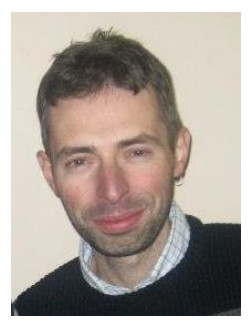

Carlo Barone received the $\mathrm{PhD}$. Degree in Physics (specialization Condensed Matter) from the University of Salerno, Italy, in 2008. He is currently a research associate with the Physics Department of University of Salerno. From April 2017 he has the Habilitation for Associate Professor in Experimental Condensed Matter Physics. Most of his scientific and professional activity is focused on the elaboration of stochastic signals originated by non-equilibrium processes in innovative materials and devices He has authored or co-authored almost 50 papers in peer-review journals. From 2015, he is a member of the Editorial Board of Scientific Reports (a journal of Nature Publishing Group).

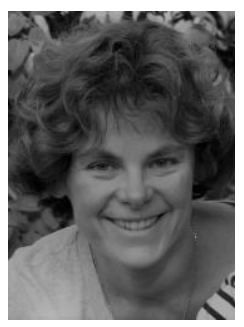

Laurence Méchin received the $\mathrm{PhD}$. Degree in electrical engineering from the University of Caen, France, in 1996. She is currently a CNRS Senior Scientist with GREYC, Caen, France. She has authored or co-authored more than 100 papers. Her research interests are the design, fabrication, and characterization of innovative materials such as functional oxides and nitrides for sensors and components.

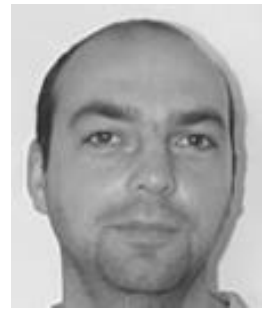

Bruno Guillet received the $\mathrm{PhD}$ and the accreditation to supervise research in Electronics-Microelectronics from the University of Caen, France, respectively in 2003 and in 2014. He is currently an associate professor in electronics with the University of Caen. His research interests include design, fabrication, and characterization of innovative materials such as functional oxides and nitrides for sensors and components. In GREYC laboratory, he is working on noise measurements, resistive thermometry and bolometers. He has authored or co-authored 35 publications in peer-review journals. 